\title{
A Simple Method to Assess Estrogen Receptor Gene (ESR1) Amplification in Paired Biopsies from Primary Tumor and Recurrence in Breast Cancer Patients Receiving Endocrine Therapy
}

Cristóbal Maiz¹, David Oddó ${ }^{2}$, Francisca Alfaro ${ }^{2}$, Alejandra Villarroll ${ }^{2}$, Francisco Acevedo $^{3}$, Alejandra Pérez Sepulveda ${ }^{3}$, Sabrina Muñiz $\mathbf{R N}^{4}$, Fernando Silva ${ }^{3}$, Andrés Valdivia ${ }^{3}$, Tomas Merino ${ }^{3}$, Mauricio $\mathbf{P}$ Pinto $^{3}$ and César Sánchez ${ }^{3 *}$

${ }^{1}$ Department of Surgical Oncology, Faculty of Medicine, Pontifical Catholic University of Chile, Chile 2Pathological Anatomy Laboratory, Faculty of Medicine, Pontifical Catholic University of Chile, Chile

${ }^{3}$ Department of Hematology Oncology, Faculty of Medicine, Pontifical Catholic University of Chile, Chile

${ }^{4}$ Hematology-Oncology Unit, Dr Sótero del Río Healthcare Complex, Chile

*Corresponding author: César Sánchez, Department of Hematology-Oncology; Faculty of Medicine Pontifical Catholic University

of Chile, Chile

\section{ARTICLE INFO}

Received: 幽 January 28, 2020

Published: 蔧 February 05, 2020

Citation: Cristóbal Maiz, David Oddó, Francisca Alfaro, Alejandra Villarroel, Francisco Acevedo, Alejandra Pérez Sepulveda, Sabrina Muñiz RN, Fernando Silva, Andrés Valdivia, Tomas Merino, Mauricio P Pinto, César Sánchez. A Simple Method to Assess Estrogen Receptor Gene (ESR1) Amplification in Paired Biopsies from Primary Tumor and Recurrence in Breast Cancer Patients Receiving Endocrine Therapy. Biomed J Sci \& Tech Res 25(2)2020. BJSTR. MS.ID.004188.

\section{ABSTRACT}

Globally, Breast Cancer (BC) is the leading cause of cancer death among women. About $75 \%$ of patients are diagnosed with hormone-dependent tumors and are set to receive Endocrine Therapy (ET) targeting the estrogen receptor. Unfortunately, a significant proportion of these patients develops ET resistance. Still controversial, studies have proposed that Estrogen Receptor-Alpha Gene (ESR1) alterations may underlie ET resistance. Here, we describe the use of a Chromogenic in Situ Hybridization (CISH) assay for the assessment of ESR1 amplification in primary tumors and recurrences. This assay could be a useful clinical tool with therapeutic implications for estrogen receptor positive BC patients.

Keywords: ESR1; Breast Cancer; Estrogen-Receptor Amplification; Endocrine Therapy; Endocrine Therapy Resistance

Abbreviations: ET: Endocrine Therapy; CISH: Chromogenic in Situ Hybridization; BC: Breast Cancer; FFPE: Formalin-Fixed Paraffin Embedded; HER-2: Human Epidermal Growth Factor Receptor Type-2; ISH: In Situ Hybridization

\section{Introduction}

Worldwide, Breast Cancer (BC) remains as the leading cause of cancer-related death for women [1]. Approximately a $75 \%$ of breast tumors stain positive for the Estrogen Receptor (ER+). Upon diagnosis, ER+ BC patients are candidates to Endocrine Therapy (ET). Indeed, positivity for ER in tumors is a predictor for ET responsiveness [2,3]. Also, tumoral ER expression has prognostic implications, ER+ BC patients that receive ET display better survival rates versus ER- counterparts [4-6]. Furthermore, in early stage ER+ BC patients ET reduces mortality by 50\% [4]. However, almost $25 \%$ of these patients will eventually develop ET resistance. Among metastatic ER+ BC patients, this \% is much higher. Clinically, ET resistance is manifested as recurrent disease during or after adjuvant treatment [3]. For these patients, metastasis is the main cause of death [7]. Studies have postulated a variety of ET resis- 
tance mechanisms, however one of the best described to date is ER-alpha gene (ESR1) amplification [8]. In fact, ESR1 amplification has been described in both primary tumors and metastases [9-11]. Currently, the assessment of gene amplification is a standard procedure routinely performed in pathology laboratories.

For example, Human Epidermal Growth Factor Receptor Type2 (HER2) gene amplification is routinely determined by In Situ Hybridization (ISH) using Formalin-Fixed Paraffin Embedded (FFPE) tissue from mammary neoplasms for BC diagnosis. Herein, we report ESR1 amplification in paired biopsies (primary tumor and recurrence) from $\mathrm{BC}$ patients that developed ET resistance. To the best of our knowledge, this is the first report on this clinically relevant method using paired samples from primary tumor and its recurrence.

\section{Materials and Methods}

\section{Study Design and Ethics Approval}

This study is an observational, retrospective patient series. Research was approved by ethics committee at the School of Medicine in the Pontificia Universidad Catolica de Chile (approval \#190605010, dated on August 1st, 2019).

\section{Patients, Samples and Clinical Data}

Patients with ER+ BC at diagnosis who were treated with ET and recurred during or after finishing treatment were selected from our database. Stage IV patients were excluded. FFPE tissue of tumors were obtained from a biobank. Anonymized demographics and clinical data were obtained from institutional database.

ESR1 Gene Amplification Assessment by Chromogenic in Situ Hybridization

FFPE blocks were sectioned at $5 \mathrm{um}$. After deparaffinization and hydration, a commercial ZytoLight $®$ SPEC ESR1/CEN 6 Dual Color Probe (cat\# Z-2069-200; ZytoVision GmbH, Germany) was used, following manufacturer's instructions. After ISH procedure, samples were blindly evaluated by an expert pathologist. ESR1 amplification was defined as a ratio of ESR1 to centromere at $\geq 4$.

\section{Statistical Analysis}

Descriptive statistical analysis was used. Parametric or nonparametric tests were used when appropriate. Also, Spearman or Pearson correlations were assessed. Statistical significance was set at $\mathrm{p}<0.05$. For data analysis, STATA v.14 and GraphPad Prism v7.0. software were used.

\section{Results}

Patients' basic characteristics are summarized in Table 1. Median age was 50.5 years (range: $37-73$ ). Histologically, $85 \%$ of patient samples were classified as ductal carcinoma, and a $64.28 \%$ were treated with tamoxifen prior to ET resistance. Median recurrence free survival was 36 months (range: 11-219). A total of 14 paired biopsies (primary tumor and recurrence) from ER+ BC were analyzed. Figure 1 shows two invasive ductal carcinomas with or without ESR1 amplification in upper and lower panels, respectively. Left panels show hematoxylin \& eosin stains. Right panels show ESR1/CEN6 stains. Note the presence of several positive nuclei in the upper right panel. Overall, a $23 \%$ of primary tumors $(3 / 10)$ were ESR1-amplification+, whereas in recurrence was 50\% (4/8). Also, in 3 out of 7 cases (42.9\%) we observed discrepancies in ESR1-amplification status between the primary tumor and the recurrence; Within this subset, 2 went from ESR1-amplificationto + (primary versus recurrence), and 1 recurrence lost the ESR1amplification observed in the primary tumor. Additionally, patients with recurrent disease and ESR1-amplification+ tended to be older (63 versus 51 years, respectively), displayed higher BMI index and ER expression. They also had shorter disease-free survival rates against patients that changed their status from ESR1-amplification+ to - status. Unfortunately, all these differences were not statistically significant.

Table 1: Patients' basic characteristics by ESR1-amplification status.

\begin{tabular}{|c|c|c|c|c|c|}
\hline \multirow[b]{2}{*}{ Characteristics } & \multicolumn{2}{|c|}{ ESR1 status on primary tumor } & \multicolumn{2}{|c|}{ ESR1 status recurrence on biopsy } & \multirow[b]{2}{*}{ p-value } \\
\hline & Not Amplified $(n=10)$ & Amplified $(n=3)$ & Not Amplified $(n=4)$ & Amplified ( $n=4)$ & \\
\hline Age at diagnosis (years) & $50.5(37-73)$ & $50(45-61)$ & $47(37-52)$ & $63.5(61-73)$ & 0.14 \\
\hline BMI $\left(\mathrm{m} / \mathrm{Kg}^{2}\right)$ & $25 \pm 4.27$ & $27 \pm 1.83$ & $28.1 \pm 5.20$ & $30.6 \pm 4.70$ & 0.29 \\
\hline Tumor size $(\mathrm{cm})$ & $5.72 \pm 2.71$ & $1.05 \pm 0.35$ & $5.1 \pm 3.80$ & $1.95 \pm 0.07$ & 0.14 \\
\hline № compromised lymph nodes & $3.5(1-15)$ & 0 & $1(1-3)$ & $3(2-4)$ & 0.053 \\
\hline \% Compromised lymph nodes & $21.75 \pm 13.28$ & 0 & $13.68 \pm 17.45$ & $63.33 \pm 51.85$ & 0.079 \\
\hline \% ER expresion & $79.88 \pm 13.68$ & $73.0 \pm 37.51$ & $90.5 \pm 11.09$ & $91.75 \pm 8.80$ & 0.50 \\
\hline \% PR expression & $46.25 \pm 40.95$ & $60.0 \pm 36.06$ & $58.33 \pm 38.84$ & $26.67 \pm 37.86$ & 0.50 \\
\hline Time to recurrence (months) & $45(16-219)$ & $33(11-35)$ & $62,5(24-147)$ & $28.5(11-219)$ & 0.46 \\
\hline
\end{tabular}

*ESR1: Estrogen Receptor-Alpha Gene; BMI: Body Mass Index; ER: Estrogen Receptor; PR: Progesterone Receptor. 


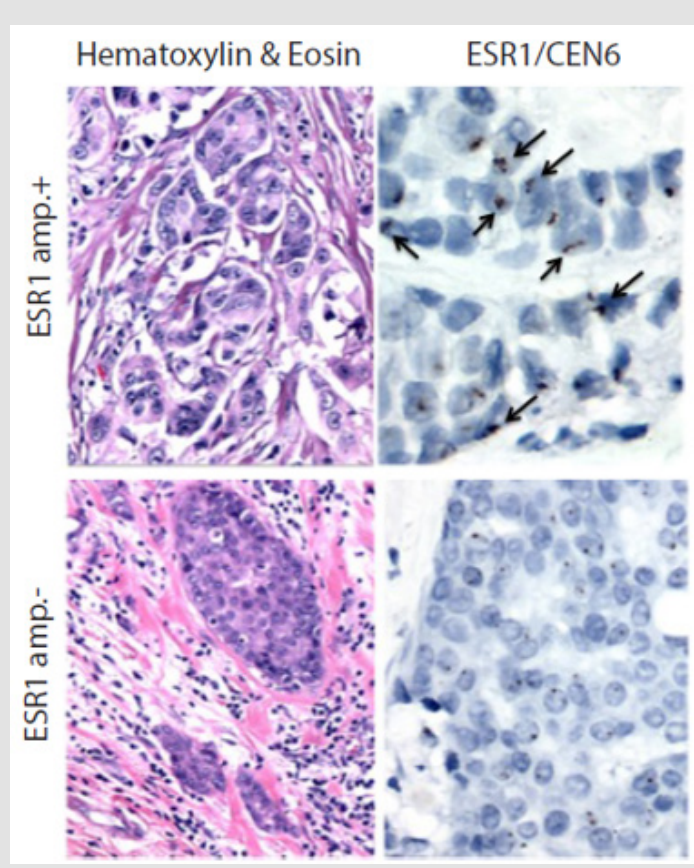

Figure 1: Analysis of ESR1 amplification status on invasive ductal carcinoma biopsies. Left panels show Hematoxylin \& Eosin stains. Right panels show Chromogenic in Situ Hybridization (CISH) stains against ESR1/CEN6. Upper panel shows a patient ESR1-amplification+ (ESR1-amp. +), arrows indicate positive nuclei (upper right). Lower panel shows a patient ESR1amplification-. Magnification: 1,000x.

\section{Discussion}

To the best of our knowledge, this is the first report on ESR1amplification by CISH on paired samples from primary tumors and metastases obtained from ER+ BC patients. As reported previously, our data suggest ESR1 amplification is more frequently observed in recurrent tumors. Previous studies in early ER+BC patients demonstrate ESR1 genomic alterations are rare, ranging from $2-5 \%$ [12-14], suggesting they are not related to carcinogenesis [15]. In contrast, ESR1 alterations are far more frequent among metastatic ER+ BCs, ranging from 20-55\% [16,17], suggesting a role in metastasis. Massive sequencing technologies and the development of collaborative efforts like The Cancer Genome Atlas (TCGA) have helped to elucidate the genomic complexity of BC. These studies have demonstrated that copy number alterations are commonly seen in the ESR1 gene. Furthermore, ESR1 amplifications are related to increases in functional ER protein. Concomitantly, several point mutations can affect the ER-Ligand Binding Domain (LBD), generating a ligand-independent constitutively active-ER [18]. Mutant ER variants may play a role in ET resistance in patients and may confer some advantages to expressing cancer cells, favoring proliferation in estrogen-deprived conditions or even in the presence of ET drugs such as tamoxifen or fulvestrant $[19,20]$. Indeed, studies demonstrate that both tamoxifen and fulvestrant can inhibit the activity of wild-type and mutant-ERs, however inhibition of mutant ER requires higher doses, suggesting that mutant receptors play a role in ET resistance $[19,20]$.

Previously, studies have demonstrated that the rate of ESR1 amplification in BC is about $20 \%$ in both primary tumors and metastases [9-11]. Therefore, ET resistance cannot be fully attributed to this phenomenon. However, the amplification of mutant ESR1 variants may play a role in ET resistance. Interestingly, we found that 3 out of 10 (42.9\%) displayed ESR1 amplification in primary tumors and 4 out of $8(50 \%)$ had it at recurrence. Evidently, our study has certain limitations including the number of cases analyzed, also we did not assess point mutations on ESR1. Future studies should confirm our findings and elucidate the role of ESR1 amplification on the development of ET resistance.

\section{Acknowledgement}

None.

\section{Conflicts of Interest}

The authors declare no conflicts of interest.

\section{References}

1. Bray F, Ferlay J, Soerjomataram I, Siegel RL, Torre LA, et al. (2018) Global cancer statistics 2018: GLOBOCAN estimates of incidence and mortality worldwide for 36 cancers in 185 countries. CA Cancer J Clin 68(6): 394424.

2. Williams N, Harris LN (2014) The renaissance of endocrine therapy in breast cancer. Curr Opin Obstet Gynecol 26(1): 41-47.

3. Mark Taketo M (2011) Reflections on the spread of metastasis to cancer prevention. Cancer Prev Res 4(3): 324-328.

4. Zhang K, Hong R, Xu F, Xia W, Kaping L, et al. (2018) Clinical value of circulating ESR1 mutations for patients with metastatic breast cancer: A meta-analysis. Cancer Manag Res 10: 2573-2580.

5. Huang B, Warner M, Gustafsson JA (2015) Estrogen receptors in breast carcinogenesis and endocrine therapy. Mol Cell Endocrinol 418: 240244. 
6. (2005) Early Breast Cancer Trialists Collaborative Group. Effects of chemotherapy and hormonal therapy for early breast cancer on recurrence and 15-year survival: An overview of the randomised trials. Lancet 365(9472): 1687-1717.

7. Glück S (2014) Extending the clinical benefit of endocrine therapy for women with hormone receptor-positive metastatic breast cancer: Differentiating mechanisms of action. Clin Breast Cancer 14(2): 75-84.

8. Obiorah I, Jordan VC (2011) Progress in endocrine approaches to the treatment and prevention of breast cancer. Maturitas 70(4): 315-321.

9. Peng J, Sengupta S, Jordan VC (2009) Potential of selective estrogen receptor modulators as treatments and preventives of breast cancer Anticancer Agents Med Chem 9(5): 481-499.

10. Sánchez R C, Valenzuela V Y, Sepúlveda P (2018) A Systemic therapy for estrogen receptor positive advanced breast cancer. Rev Cirugia 70(5).

11. Howell A (2006) Pure oestrogen antagonists for the treatment of advanced breast cancer. Endocr Relat Cancer 13(3): 689-706.

12. Cigler T, Goss PE (2007) Breast cancer adjuvant endocrine therapy. Cancer J 13: 148-155.

13. Musgrove EA, Sutherland RL (2009) Biological determinants of endocrine resistance in breast cancer. Nat Rev Cancer 9(9): 631-643.

\section{ISSN: 2574-1241}

DOI: $10.26717 / B J S T R .2020 .25 .004188$

César Sánchez. Biomed J Sci \& Tech Res

cC) This work is licensed under Creative

Submission Link: https://biomedres.us/submit-manuscript.php
14. Osborne CK, Schiff R (2011) Mechanisms of Endocrine Resistance in Breast Cancer. Annu Rev Med 62: 233-247.

15. Jeselsohn R, Buchwalter G, De Angelis C, Brown M, Schiff R (2015) ESR1 mutations-a mechanism for acquired endocrine resistance in breast cancer. Nat Rev Clin Oncol 12(10): 573-583.

16. Roodi N, Bailey LR, Kao WY, Verrier CS, Yee CJ, et al. (1995) Estrogen receptor gene analysis in estrogen receptor-positive and receptornegative primary breast cancer. J Natl Cancer Inst 87(6): 446-451.

17. Li S, Shen D, Shao J, Crowder R, Liu W, et al. (2013) Endocrine-TherapyResistant ESR1 Variants Revealed by Genomic Characterization of Breast-Cancer-Derived Xenografts. Cell Rep 4(6): 1116-1130.

18. Toy W, Shen Y, Won H, Green B, Sakr RA, et al. (2013) ESR1 ligandbinding domain mutations in hormone-resistant breast cancer. Nat Genet 45(12): 1439-1445.

19. Merenbakh-Lamin K, Ben-Baruch N, Yeheskel A, Soussan Gutman L, Jeselsohn R, et al. (2013) D538G mutation in estrogen receptor- $\alpha$ : A novel mechanism for acquired endocrine resistance in breast cancer Cancer Res 73(23): 6856-6864.

20. Angus L, Beije N, Jager A, Martens JW, Sleijfer S (2017) ESR mutations: Moving towards guiding treatment decision-making in metastatic breast cancer patients. Cancer Treatment Reviews 52: 33-40.

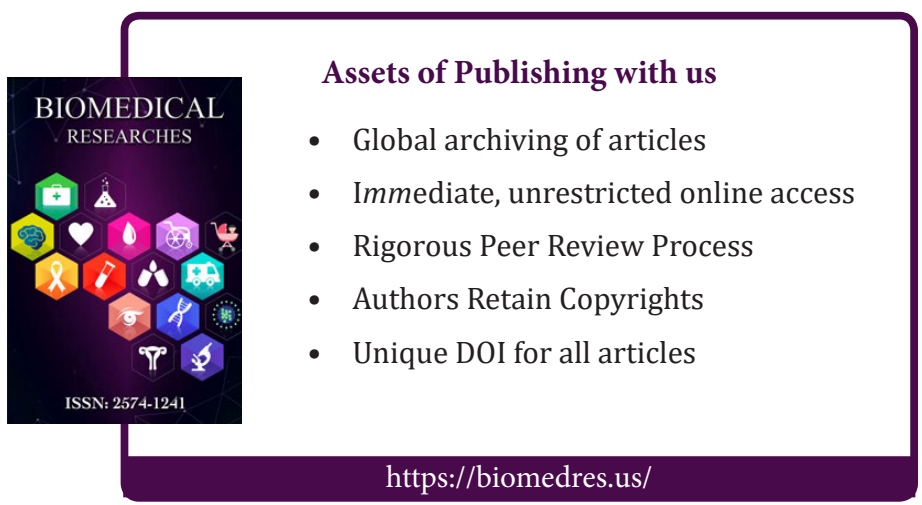

